
\title{
25 Research Square \\ Influence of Insurance Type on Rate and Type of Initial Concussion-Related Medical Visits among Youth
}

\section{Chris Radlicz}

Center for Injury Research and Policy at Nationwide Children's Hospital

Kenneth Jackson

Biostatistics Resource at Nationwide Children's Hospital

Amanda Hautmann

Center for Injury Research and Policy at Nationwide Children's Hospital

Junxin Shi

Center for Injury Research and Policy at Nationwide Children's Hospital

Jingzhen (Ginger) Yang ( $\nabla$ ginger.yang@nationwidechildrens.org )

Ohio State University https://orcid.org/0000-0003-4019-0999

Research article

Keywords: Traumatic Brain Injury, Insurance, Health care utilization, Children

Posted Date: December 1st, 2020

DOI: https://doi.org/10.21203/rs.3.rs-115161/v1

License: (c) (1) This work is licensed under a Creative Commons Attribution 4.0 International License.

Read Full License

Version of Record: A version of this preprint was published at BMC Public Health on August 18th, 2021.

See the published version at https://doi.org/10.1186/s12889-021-11586-y. 


\section{Abstract}

Background: A growing number of studies report increased concussion-related health care utilization in recent years, but factors impacting care-seeking behaviors among youth following a concussion are not well described. This study aimed to evaluate the influence of insurance type on the rate and type of initial concussion visits and the time from injury to the initial visit in youth.

Methods: We extracted and analyzed initial concussion-related medical visits for youth ages 10 to 17 from electronic health records. Patients must have visited Nationwide Children's Hospital's (NCH) concussion clinic at least once between $7 / 1 / 2012$ and 12/31/2017. We evaluated the trends and patterns of initial concussion visits across the study period using regression analyses.

Results: Of 4,955 unique concussion visits included, $60.1 \%$ were males, $80.5 \%$ were white, and $69.5 \%$ were paid by private insurance. Patients' average age was 13.9 years $(S D=3.7)$. The rate of the initial concussion visits per $10,000 \mathrm{NCH}$ visits was consistently higher in privately insured than publicly insured youth throughout the study period $(P<.0001)$. Privately insured youth had greater odds of initial concussion visits to sports medicine clinics $(A O R=1.45,95 \% \mathrm{Cl}=1.20,1.76)$ but lower odds of initial concussion visits to the $\mathrm{ED} /$ urgent care $(\mathrm{AOR}=0.74,95 \% \mathrm{Cl}=0.60,0.90)$ than publicly insured youth. Days from injury to initial concussion visit significantly decreased among both insurance types throughout the study $(P<.0001)$, with a greater decrease observed in publicly insured than privately insured youth $(P=.011)$.

Conclusions: Results on the differences in the rate, type, and time of initial concussion-related visits may help inform more efficient care of concussion among youth with different types of insurance.

\section{Background}

Concussion, a form of mild traumatic brain injury, affects approximately 2 million youth in the United States annually.[1, 2] In recent years, youth concussion has received increased attention due to growing evidence of the lasting effects on developing brains affecting physical, cognitive, emotional, and sleep health.[3, 4] If left untreated or mismanaged, a concussion can impair quality of life beyond acute symptomology[4-6] and increase the risk of repeat injury.[7] To help mitigate the consequences of concussion, all 50 states and the District of Columbia enacted concussion laws between 2009 and 2014 to promote secondary prevention efforts.[8] These laws share three core elements: (1) removal from play following a suspected or apparent concussion; (2) medical clearance approved by a licensed health professional to return to play; and (3) education for parents, student-athletes, and coaches regarding concussion signs and symptoms.[8] Early evaluation of these laws show an increase in youth concussion rates and related healthcare utilization attributed to increased recognition, awareness, and reporting.[915] Though a growing number of studies report increased concussion-related healthcare utilization, how these care-seeking behaviors are influenced by insurance status and type remains undetermined.[10, 12, 16] 
Existing evidence indicates that publicly insured youth seeking care for concussion may have limited provider options, decreased outpatient rehabilitation choices, increased barriers to specialty care, and increased wait times.[17-20] Furthermore, publicly insured youth may have higher unmet needs and poorer outcomes after concussion compared to their privately insured counterparts.[21] Concussionrelated visits for both publicly and privately insured youth increased in recent years due, in part, to concussion laws requiring youth to seek medical care for concussive injury in order to return to play.[10, 15 , 22] Moreover, studies indicate an increase in the initial concussion-related emergency department (ED) visits for publicly insured youth relative to privately insured youth.[15, 22] Publicly insured youth are more likely to use the ED as an initial point of entry for concussion treatment compared to privately insured youth,[23] while studies of privately insured youth show greater increases in primary care and specialty care.[10, 24]

Though the number of youth concussion studies continues to rise, there remains a paucity of studies outside of the ED setting or in populations other than high school and college athletes.[10, 14, 23, 24] Moreover, the few studies analyzing the influence of insurance type on concussion-related care utilization forgo an examination of how insurance type guides concussion care seeking behaviors, where care is sought, and when care is sought.[14, 23] Using the electronic health record (EHR) system in a large pediatric healthcare network, we aimed to describe the influence of insurance type on the rate of the initial concussion visit, the type of initial visit sought, and the time from injury to the initial concussion visit. We hypothesized that a higher rate of initial concussion visits would be observed among privately insured youth than publicly insured youth; that compared to privately insured youth, publicly insured youth would be more likely to visit the ED or urgent care but less likely to visit sports medicine clinics for their initial concussion care; and that days from injury to initial concussion visit would decrease throughout the study regardless of insurance type.

\section{Methods}

\section{Study data and case definition}

We retrospectively analyzed medical visits for pediatric concussions extracted from electronic health records (EHR) collected as part of routine clinical care for patients seen at Nationwide Children's Hospital $(\mathrm{NCH})$. NCH EHR uses a comprehensive and integrated set of clinical software systems to manage and record various patient care data domains such as demographics, medical visits, diagnoses, orders, and provider information that can be extracted to support data-driven research endeavors. For this study, we defined medical visits for concussions using the following International Classification of Diseases, Ninth and Tenth Revisions, Clinical Modification (ICD-9-CM and ICD-10-CM) codes: 850.0, 850.1, 850.11, 850.12, 850.2, 850.3, 850.4, 850.5, 850.9, and those beginning with S06.0.[10] We extracted the following data elements from the EHR for each concussion: basic demographics (e.g., date of birth, sex, race) and medical visit information (e.g., diagnostic codes, date of injury, date and type of visit, date of first visit, date of symptom resolution, payor). Additional data regarding the total number of all-cause first medical 
visits during the study period were also extracted. This study was approved by the Institutional Review Board of the primary authors' institution.

\section{Study population}

The population in this study was youth ages 10 to 17 years old who had a confirmed isolated concussion diagnosis, had medical visits for one or more concussions between July 1, 2012, and December 31, 2017 (not necessarily date of injury), and visited one of seven $\mathrm{NCH}$ concussion clinics at least once for their concussion treatment. Each medical visit for a unique concussion was determined by the date and time of the visit. Patients with repeated concussions were preceded by at least 90 days without an additional concussion diagnosis. We used the date of injury, date of the first visit, and date of symptom resolution to differentiate each unique concussion and included these in the analysis.

Patients were excluded if: 1) they were also diagnosed with a more severe TBI within 2 weeks of the initial concussion visit; or 2) they were receiving ongoing concussion treatment during the study period, but the patient's first medical visit occurred before July 1, 2012.

A total of 5,211 initial concussion visits were identified, with 4,955 meeting criteria for analysis. Figure I presents the exclusion process for initial visits to arrive at the final sample used in the analysis.

\section{Study variables and measures}

Rates of initial concussion visits were calculated as the number of first medical visits among youth with concussions in a year divided by the total number of first medical visits of NCH patients in the same year, then multiplied by 10,000 .

Type of initial concussion visit was classified as 1=Sports Medicine; $2=E D$, including ED or urgent care centers; and $3=0$ ther, for all other specialties.[23]

Days from injury to initial concussion visit were measured as the number of days from date of injury to date of first medical visit.

Insurance type was measured based on insurance plans across all medical visits associated with each injury (1=Public (e.g., Medicaid), 2=Private, 3=Self-pay, and 4=0ther). Self-pay and other were later collapsed together. Injuries with differing insurance plans across medical visits were labeled as other.

Other variables included patient demographics (e.g., age, sex, race), season (quarter 1 to 4) and calendar year of medical visit (calendar year from 2012 to 2017).

\section{Statistical analyses}


We described and compared demographic and injury characteristics of the study participants across different insurance types using chi-square tests. We examined trends across years and their potential interaction with insurance type via statistical models. Specifically, we employed Poisson regression to model the rate of initial healthcare visits for concussions versus initial visits for all causes, logistic regression to assess the proportion of concussion-related initial visits to sports medicine at $\mathrm{NCH}$ (or to ED) vs. otherwise, and linear regression (with log-transformed outcome) to determine the number of days from injury to initial visit to $\mathrm{NCH}$. In all regression analyses listed above, we used hierarchical modeling to account for a patient with multiple concussions by nesting these injuries within a patient and assessed the interactions between year and insurance type. Further, we adjusted for study year and season, patient age, sex, and race (patient race was not included in the Poisson regression analysis since denominator information was not available at that level). Data were analyzed using SAS (version 9.4, SAS Institute Inc, Cary, NC), and a statistical significance level was set a priori for each test at $\mathrm{a}=0.05$.

\section{Results}

Of 4,955 unique concussions included, $69.5 \%$ of initial concussion visits were paid by private insurance and $15.0 \%$ were paid by public insurance (Table I). The "other" insurance group $(n=771,15.6 \%)$, including self-pay $(n=43)$ and pay by mixed public or private insurance and/or self-pay $(n=728)$, was not included in the further regression analyses. Concussion patients were primarily male $(60.1 \%)$, white $(80.5 \%)$, and had an average age of $13.9(S D=3.7)$ at initial concussion visit. A significantly higher proportion of concussion visits were observed in publicly insured males than privately insured males $(69.3 \%$ vs $58.2 \%, P<.0001)$ and publicly insured black youth than privately insured black youth $(27.4 \%$ vs. $6.3 \%, P<.0001)$. 
Table I

Patient Demographics by Insurance Type, 2012-2017 ( $N=4,955)$

\begin{tabular}{|c|c|c|c|c|c|}
\hline Characteristic & & $\begin{array}{l}\text { Private Insurance } \\
(n=3,442)\end{array}$ & $\begin{array}{l}\text { Public Insurance } \\
(\mathrm{n}=742)\end{array}$ & $\begin{array}{l}\text { Other } \\
(n=771)\end{array}$ & $P$ Value ${ }^{\text {a }}$ \\
\hline \multirow[t]{3}{*}{ Sex, No. (\%) } & & & & & $<0.0001$ \\
\hline & Male & $2,004(58.2)$ & $514(69.3)$ & $462(59.9)$ & \\
\hline & Female & $1,438(41.8)$ & $228(30.7)$ & $309(40.1)$ & \\
\hline \multirow[t]{3}{*}{ Age, No. (\%), y } & & & & & $<0.05$ \\
\hline & $10-13$ & 1365 (39.7) & $310(41.8)$ & $309(40.1)$ & \\
\hline & $14-17$ & $2077(60.3)$ & $432(58.2)$ & $462(59.9)$ & \\
\hline \multirow[t]{6}{*}{ Race, No. (\%) } & & & & & $<0.0001$ \\
\hline & White & $3,003(87.3)$ & $434(58.5)$ & $550(71.3)$ & \\
\hline & Black & $217(6.3)$ & $203(27.4)$ & $133(17.3)$ & \\
\hline & Multiple & $148(4.2)$ & $64(8.6)$ & $70(17.3)$ & \\
\hline & Other & $46(1.3)$ & $9(1.2)$ & $8(1.0)$ & \\
\hline & Unknown & $28(0.8)$ & $32(4.3)$ & $10(1.3)$ & \\
\hline \multirow[t]{4}{*}{ Ethnicity, No. (\%) } & & & & & $<0.0001$ \\
\hline & Non-Hispanic & $3,306(96.1)$ & $675(91.0)$ & $713(94.8)$ & \\
\hline & Hispanic & $12(0.4)$ & $35(4.7)$ & $13(1.7)$ & \\
\hline & Unknown & $124(3.6)$ & $32(4.3)$ & $27(3.5)$ & \\
\hline \multicolumn{2}{|l|}{ Study Year, No. (\%) } & & & & $<0.0001^{\mathrm{c}}$ \\
\hline & $2012^{\mathrm{b}}$ & $367(10.7)$ & $70(9.4)$ & $88(11.4)$ & \\
\hline & 2013 & $659(19.1)$ & $118(15.9)$ & $164(21.3)$ & \\
\hline & 2014 & $610(17.7)$ & $146(19.7)$ & $163(21.1)$ & \\
\hline & 2015 & $643(18.7)$ & $132(17.8)$ & $152(19.7)$ & \\
\hline & 2016 & $641(18.6)$ & $153(20.6)$ & $127(16.5)$ & \\
\hline & 2017 & $522(15.2)$ & $123(16.6)$ & $77(10.0)$ & \\
\hline \multicolumn{6}{|c|}{ a Based on chi-square tests of the distribution between insurance types } \\
\hline b Quarter 3 and 4 & & & & & \\
\hline
\end{tabular}




\section{Rate of initial concussion visit by insurance type}

The rate of the initial concussion visits per $10,000 \mathrm{NCH}$ visits was consistently higher during the study period for privately insured youth compared to publicly insured youth $(\beta=1.9719, P<.0001)$ (Figure II). The overall rate of initial concussion visits decreased throughout the study period $(\beta=-0.0701, P<.0001)$, with a greater decrease in rate for privately insured visits compared to publicly insured visits $(\beta=-0.1008$, $P<.0001)$. Specifically, the rate of initial concussion visits among privately insured youth decreased from a peak of 150.7 per 10,000 in 2013 to 70.1 per 10,000 in 2017 , while rate of initial concussion visits among public insurance decreased from 23.1 per 10,000 in 2013 to 17.2 per 10,000 in 2017. 
Table II

Odds Ratios (OR) of Type of Initial Concussion-related Visits, 2012-2017 ( $\mathrm{n}=4,184$ )

\begin{tabular}{llllll}
\multicolumn{2}{l}{ ED and Urgent Care vs. All Others } & \multicolumn{3}{l}{ Sports Medicine Clinic vs. All Others } \\
$\begin{array}{llll}\text { Adjusted } \\
\mathrm{OR}^{\mathrm{a}}\end{array}$ & $(95 \% \mathrm{Cl})$ & $p$-value & $\begin{array}{l}\text { Adjusted } \\
\mathrm{OR}^{\mathrm{a}}\end{array}$ & $(95 \% \mathrm{Cl})$ & $p$-value \\
\hline
\end{tabular}

Insurance

Type

$\begin{array}{lcccccc}\text { Private } & 0.74 & (0.60, & 0.0002 & 1.45 & (1.20, & 0.0002 \\ \text { Public } & \text { Ref } & & & 1.76)^{\prime} & \\ \text { Sex } & & & \text { Ref } & & \\ \text { Male } & \text { Ref } & & & \text { Ref } & & \\ \text { Female } & 0.97 & \begin{array}{l}(0.82, \\ 1.14)\end{array} & 0.6959 & 1.00 & (0.86, & 0.9711 \\ & & & & & 1.18) & \end{array}$

Age, $y$

$10-13$

Ref

Ref

$14-17$

0.30

(0.25,

$0.34)$

3.26

<. 0001

(2.81,

3.78)

$<0.0001$

Race

White

Ref

Ref

Black

1.33

(1.03,

0.74

0.0290

(0.58,

$0.95)$

All others

1.15

(0.87,
1.52)

$0.3344 \quad 0.88$

(0.67,

(1.13,

1.25)

$<\quad 0.82$

$(0.78$,

$0.86)$

Season

Quarter 1

Ref

Ref

Quarter 2

0.84

(0.65,

1.09)

$0.1889 \quad 1.20$

$(0.94$

1.54)

0.1429

Quarter 3

0.91

(0.73,

1.13)

$0.3973 \quad 1.09$

(0.88,

1.34)

Quarter 4

0.84

(0.67)
$1.06)$

0.1370

1.17

(0.94,

1.46)

0.0158

0.3604

$<0.0001$

Note. OR=Odds Ratio; $\mathrm{Cl}=$ Confidence Interval. 
a. Odds ratio was based on logistic regression adjusted for all the variables listed in the table.

b. 2012 included data from Quarter 3 and 4 only

\section{Type of initial concussion visit by insurance type}

Privately insured youth were 1.45 times as likely to have initial concussion visits to sports medicine clinics $(95 \% \mathrm{Cl}=1.20,1.76)$ but 0.74 times as likely to have initial concussion visits to the ED/urgent care $(95 \% \mathrm{Cl}=0.60,0.90)$ as compared to publicly insured youth, after adjusting for patient age, sex, race, study year, and season (Table II). Initial concussion visits to the ED and urgent care significantly increased from 2012 to 2017 , with adjusted odds ratio $(\mathrm{OR})$ of $1.19(95 \% \mathrm{Cl}=1.13,1.25)$ for each advanced study year. However, initial concussion visits to sports medicine clinics significantly decreased during the same period, with adjusted OR of $0.82(95 \% \mathrm{Cl}=0.78,0.86)$ for each advanced study year.

\section{Time from injury to initial concussion visit by insurance type}

The time from injury to initial concussion visit significantly decreased among both insurance groups throughout the study $(\beta=-0.1821, P<.0001)$ (Figure III). Furthermore, privately insured youth had a significantly shorter time from injury to initial visit than publicly insured youth $(\beta=-0.3842, P=.0008)$. Finally, a significant interaction between study year and insurance type was observed $(\beta=0.0807, P=$ .0106), with a significantly larger decrease in days from injury to initial concussion visit from 2012 to 2017 in publicly insured youth (16.8 to 7.1 days) than privately insured youth (12.3 to 7.8 days).

\section{Discussion}

This study used a linked EHR system to evaluate the influence of insurance type on the rate, type, and time of initial medical visit following a concussion in a large pediatric hospital network between 2012 and 2017. The results of the study supported all three of our hypotheses. We found that privately insured youth had a significantly higher rate of initial concussion visits throughout the study than publicly insured youth. Furthermore, publicly insured youth were significantly more likely to seek initial concussion-related care at the ED and urgent care but less likely to seek initial concussion-related care at a sports medicine clinic than privately insured youth. Finally, days from injury to initial concussion visit significantly decreased among both insurance types throughout the study, with a greater decrease observed in publicly insured youth. Our study demonstrates that the rate, type, and time of initial concussion-related visits are different between insurance types in a large pediatric healthcare network. Our study leveraged the EHR of a large pediatric healthcare network to capture youth concussion careseeking behaviors beyond the emergency setting, including the outpatient setting, where the majority of pediatric patients seek concussion care.[1, 25] 
The higher rate of initial concussion visits in the privately insured than the publicly insured youth observed in this study may be explained by greater participation in sports and more weekly hours in organized sports among youth of higher-income households.[26] Considering that injury during sports is the primary cause of concussion in youth and adolescents, privately insured youth would be more likely to sustain a concussion than publicly insured youth. $[16,27,28]$ In studies of multiple states, enactment of concussion laws initially increased concussion-related visits, with the rate leveling-off or decreasing after a few years into the post law-period.[9-11] Though heightened public awareness as a result of educational efforts such as the Centers for Disease Control and Prevention's "Heads Up" campaign[29] is cited as a reason for increased concussion-related visits, $[10,11,15]$ the decreased rate observed in our study is consistent with prior studies of the Ohio law, which reported overall decreases in concussionrelated visits in sports medicine clinics and EDs after the law's passage.[14, 15] The observed decreased rate may be due in part to the guidelines on minimal body contact during sport practices[3] or the decrease in contact-sports participation across the nation[30,31] which could be responsible for the greater decrease in rate of concussion visits seen in privately insured youth as well. Future studies should identify both the mechanism of injury and type of sport precipitating the concussion to better describe these evolving trends.

Consistent with previous study findings,[32] we found that publicly insured youth were more likely to seek initial concussion-related care at the ED and urgent care than privately insured youth. Previous studies show that publicly insured children are more reliant on the ED for medical care than those with private insurance[32] and that publicly insured pediatric patients increased ED visits relative to privately insured after the passage of concussion laws.[22] We also found that youth with public insurance were less likely than those with private insurance to visit a sports medicine clinic for their initial concussion-related care although the sports medicine clinic remained the main location for the majority of initial concussion visits throughout the study regardless of insurance type. A study of another pediatric healthcare network found primary care as the initial point of healthcare entry for $82 \%$ of a pediatric patients.[23] Furthermore, the study reported a decrease in use of ED and urgent care as a point of healthcare entry from 2010 to 2014 for both publicly and privately insured.[23] The study's inclusion criteria was limited to patients whose primary care was normally delivered by a pediatrician within the hospital network. Likewise, our study was limited to those who had at least one concussion-related medical visit at one of seven $\mathrm{NCH}$ sports medicine clinics. Therefore, our study population is likely more symptomatic than youth with concussions managed by primary care physicians.[33] The reported reliance of primary care as the dominant location for concussion care[23, 24, 34, 35] may not be captured in our study due to our inclusion criteria. Because the concussion law requires medical clearance to return to play, both privately and publicly insured youth may seek care in the ED because it is perceived to expedite the processes of receiving medical clearance and the ability to return to play although providing medical clearance for concussion is not usually done by an ED physician.

The observed decrease in average time from injury to initial concussion visit for both insurance types is likely a consequence of the increase in initial concussion visits to the ED and urgent care. Emergency care is often sought in time-sensitive cases, and parity in time to initial visit is expected among public and 
private insurance types, regardless of ability to pay.[36] Though the time from concussion injury to initial visit for the publicly insured was longer than privately insured at the start of the study, the trends converged and crossed later in the study (Figure III). This change is likely due to the greater increase in initial concussion visits in the ED and urgent care among the publicly insured. A greater urgency for an initial visit may also be due to mandated medical clearance in concussion legislation and increased education for parents about concussion and its consequences.[37, 38] A shorter time to first visit following concussion is associated with faster recovery times in previous studies, so future studies should investigate how insurance type affects differences in care received until symptom resolution.[14, 39] Another possible explanation for the observed decrease in average time to initial concussion visit is an increase in availability of concussion care at $\mathrm{NCH}$, although this study did not collect data on that aspect. Further investigation is merited to determine the change in access and availability of care on the time from injury to initial care visit.

Our study should be interpreted with several limitations. First, by using the EHR system of a single healthcare network, visits outside of the network were not included in our analysis. Therefore, the first medical visit within the $\mathrm{NCH}$ network may not be the true initial visit. Second, our study was retrospective which introduces concerns of accuracy in medical coding and detail. Third, we did not report the severity of concussion or the mechanism of the injury, both of which likely influence the choice of setting and time to initial concussion visit. Fourth, we limited our inclusion criteria to youth with at least one visit at an $\mathrm{NCH}$ sports medicine clinic, potentially tilting our population toward a cohort with a greater burden of symptoms. Fifth, we did not examine self-pay or mixed-insurance status as a category due to small cell size. Therefore, uninsured children were not evaluated, omitting representation of the millions of children who remain uninsured even when eligible for public insurance.[40] Finally, our study was limited to a pediatric hospital network in central Ohio that serves those in rural, suburban, and urban areas; as such it may not be generalizable to the greater pediatric population.

\section{Conclusions}

This study evaluated initial concussion visits within a large pediatric network and used a unified EHR to determine differences in the care-seeking behaviors of publicly and privately insured youth. From 2012 to 2017, publicly insured youth had lower rates of initial concussion visits, were more likely to visit the ED and urgent care for initial concussion-related care and had a greater decrease in average time to initial concussion visit compared to privately insured youth. The differences observed between insurance types along with general trends for both insurance types require further exploration. Application of these findings may help improve the care of youth following concussion injury.

\section{Abbreviations}

Cls: Confidence intervals; ED: Emergency Department; EHR: Electronic Health Records; ICD-9-CM: International Classification of Diseases, Ninth Revision; ICD-10-CM: International Classification of Diseases, Tenth Revision; NCH: Nationwide Children's Hospital; OR: Odds ratio. 


\section{Declarations}

\section{Authors' Contributions}

JY, CR and KJ contributed to concept and design. CR drafted the initial manuscript. JY, CR, AH, KJ and JS critically reviewed and revised the manuscript for important intellectual content and contributed to interpretation of data. KJ and JS conducted statistical analysis. JY obtained funding and acquired the data. All authors reviewed and approved the final manuscript.

\section{Funding}

This research work was funded by Centers for Disease Control and Prevention National Center for Injury Prevention and Control (3 R49 CE002106-05S1). The funding body played no role in the design of the study, in the collection, analysis and interpretation of data, or in writing the manuscript.

\section{Availability of data and materials}

The datasets enabling this research are not publicly available due to privacy or ethical restrictions but are available from the corresponding author on reasonable request.

\section{Ethics approval and consent to participate}

The Institutional Review Board of the Nationwide Children's Hospital granted approval of waiver of informed consent for this research (IRB18-01171). A waiver of informed consent was obtained under 45 CFR 46.116(d) and a waiver of HIPAA Authorization was granted under 45 CFR 164.512(i). A Data User Agreement was acquired by our team to access the data used in this study.

\section{Consent for publication}

Not applicable.

\section{Competing interests}

The authors declare that they have no competing interests.

\section{References}

1. Bryan MA, Rowhani-Rahbar A, Comstock RD, Rivara F: Sports- and Recreation-Related Concussions in US Youth. Pediatrics 2016, 138(1). 
2. DePadilla L, Miller GF, Jones SE, Peterson AB, Breiding MJ: Self-Reported Concussions from Playing a Sport or Being Physically Active Among High School Students - United States, 2017. MMWR Morb Mortal Wkly Rep 2018, 67(24):682-685.

3. McCrory P, Meeuwisse W, Dvorak J, Aubry M, Bailes J, Broglio S, Cantu RC, Cassidy D, Echemendia RJ, Castellani RJ et al: Consensus statement on concussion in sport-the 5th international conference on concussion in sport held in Berlin, October 2016. British Journal of Sports Medicine 2017, 51(11):838.

4. Rivara FP, Koepsell TD, Wang J, Temkin N, Dorsch A, Vavilala MS, Durbin D, Jaffe KM: Disability 3, 12, and 24 months after traumatic brain injury among children and adolescents. Pediatrics 2011, 128(5):e1129-1138.

5. Rivara FP, Koepsell TD, Wang J, Temkin N, Dorsch A, Vavilala MS, Durbin D, Jaffe KM: Incidence of disability among children 12 months after traumatic brain injury. Am J Public Health 2012, 102(11):2074-2079.

6. Fineblit S, Selci E, Loewen H, Ellis M, Russell K: Health-Related Quality of Life after Pediatric Mild Traumatic Brain Injury/Concussion: A Systematic Review. J Neurotrauma 2016, 33(17):1561-1568.

7. Curry AE, Arbogast KB, Metzger KB, Kessler RS, Breiding MJ, Haarbauer-Krupa J, DePadilla L, Greenspan A, Master CL: Risk of Repeat Concussion Among Patients Diagnosed at a Pediatric Care Network. J Pediatr 2019, 210:13-19.e12.

8. Lowrey K: State Laws Addressing Youth Sports-Related Traumatic Brain Injury and the Future of Concussion Law and Policy. Journal of Business \& Technology Law 2015, 10(1).

9. Yang J, Comstock RD, Yi H, Harvey HH, Xun P: New and Recurrent Concussions in High-School Athletes Before and After Traumatic Brain Injury Laws, 2005-2016. Am J Public Health 2017, 107(12):1916-1922.

10. Gibson TB, Herring SA, Kutcher JS, Broglio SP: Analyzing the effect of state legislation on healthcare utilization for children with concussion. JAMA Pediatr 2015, 169(2):163-168.

11. Singichetti B, Leonard JC, Janezic AR, Li H, Yi H, Yang J: Trends in Pediatric Emergency Department Utilization for Mild Traumatic Brain Injury Before and After Legislation. J Head Trauma Rehabil 2018, 33(6):E30-E37.

12. Mackenzie B, Vivier P, Reinert S, Machan J, Kelley C, Jacobs E: Impact of a state concussion law on pediatric emergency department visits. Pediatr Emerg Care 2015, 31(1):25-30.

13. Bompadre V, Jinguji TM, Yanez ND, Satchell EK, Gilbert K, Burton M, Conrad EU, 3rd, Herring SA: Washington State's Lystedt law in concussion documentation in Seattle public high schools. J Athl Train 2014, 49(4):486-492.

14. Cuff SC, Coxe K, Young JA, Li H, Yi H, Yang J: Concussion clinic presentation and symptom duration for pediatric sports-related concussions following Ohio concussion law. Res Sports Med 2019, 27(1):11-20.

15. Tarimala A, Singichetti B, Yi H, Huang L, Doerschuk R, Tiso M, Yang J: Initial Emergency Department Visit and Follow-Up Care for Concussions among Children with Medicaid. The Journal of pediatrics 
2019, 206:178-183.

16. Sarmiento K, Thomas KE, Daugherty J, Waltzman D, Haarbauer-Krupa JK, Peterson AB, Haileyesus T, Breiding MJ: Emergency Department Visits for Sports- and Recreation-Related Traumatic Brain Injuries Among Children - United States, 2010-2016. MMWR Morb Mortal Wkly Rep 2019, 68(10):237242.

17. Fuentes MM, Thompson L, Quistberg DA, Haaland WL, Rhodes K, Kartin D, Kerfeld C, Apkon S, Rowhani-Rahbar A, Rivara FP: Auditing Access to Outpatient Rehabilitation Services for Children With Traumatic Brain Injury and Public Insurance in Washington State. Arch Phys Med Rehabil 2017, 98(9):1763-1770.e1767.

18. Bisgaier J, Rhodes KV: Auditing access to specialty care for children with public insurance. $N$ Engl J Med 2011, 364(24):2324-2333.

19. Copley M, Jimenez N, Kroshus E, Chrisman SPD: Disparities in Use of Subspecialty Concussion Care Based on Ethnicity. J Racial Ethn Health Disparities 2020.

20. Bisgaier J, Polsky D, Rhodes KV: Academic medical centers and equity in specialty care access for children. Arch Pediatr Adolesc Med 2012, 166(4):304-310.

21. Zonfrillo MR, Durbin DR, Koepsell TD, Wang J, Temkin NR, Dorsch AM, Vavilala MS, Jaffe KM, Rivara FP: Prevalence of and risk factors for poor functioning after isolated mild traumatic brain injury in children. J Neurotrauma 2014, 31(8):722-727.

22. Hardesty W, Singichetti B, Yi H, Leonard JC, Yang J: Characteristics and Costs of Pediatric Emergency Department Visits for Sports- and Recreation-Related Concussions, 2006-2014. J Emerg Med 2019, 56(5):571-579.

23. Arbogast KB, Curry AE, Pfeiffer MR, Zonfrillo MR, Haarbauer-Krupa J, Breiding MJ, Coronado VG, Master CL: Point of Healthcare Entry for Youth With Concussion Within a Large Pediatric Care Network. JAMA Pediatr 2016, 170(7):e160294-e160294.

24. Taylor AM, Nigrovic LE, Saillant ML, Trudell EK, Proctor MR, Modest JR, Vernacchio L: Trends in Ambulatory Care for Children with Concussion and Minor Head Injury from Eastern Massachusetts between 2007 and 2013. The Journal of Pediatrics 2015, 167(3):738-744.

25. Zogg CK, Haring RS, Xu L, Canner JK, AISulaim HA, Hashmi ZG, Salim A, Engineer LD, Haider AH, Bell JM et al: The Epidemiology of Pediatric Head Injury Treated Outside of Hospital Emergency Departments. Epidemiology 2018, 29(2):269-279.

26. Jayanthi NA, Holt DB, Jr., LaBella CR, Dugas LR: Socioeconomic Factors for Sports Specialization and Injury in Youth Athletes. Sports Health 2018, 10(4):303-310.

27. Haarbauer-Krupa J, Arbogast KB, Metzger KB, Greenspan Al, Kessler R, Curry AE, Bell JM, DePadilla L, Pfeiffer MR, Zonfrillo MR et al: Variations in Mechanisms of Injury for Children with Concussion. The Journal of pediatrics 2018, 197:241-248.e241.

28. Fabricant PD, McLaren SH, Suryavanshi JR, Nwachukwu BU, Dodwell ER: Association Between Government Health Insurance Status and Physical Activity in American Youth. J Pediatr Orthop 2019, 39(7):e552-e557. 
29. Stead TS, Rastogi V, Hedna VS, Ganti L: Awareness of the CDC "Heads Up!" to Youth Sports Campaign among Pediatric Sports Coaches: A Pilot Survey Study. Cureus 2016, 8(8):e755.

30. 2017-18 High School Athletics Participation Survey. In.: National Federation of State High School Associations.

31. Coronado VG, Haileyesus T, Cheng TA, Bell JM, Haarbauer-Krupa J, Lionbarger MR, Flores-Herrera J, McGuire LC, Gilchrist J: Trends in Sports- and Recreation-Related Traumatic Brain Injuries Treated in US Emergency Departments: The National Electronic Injury Surveillance System-All Injury Program (NEISS-AIP) 2001-2012. J Head Trauma Rehabil 2015, 30(3):185-197.

32. Schlichting LE, Rogers ML, Gjelsvik A, Linakis JG, Vivier PM: Pediatric Emergency Department Utilization and Reliance by Insurance Coverage in the United States. Acad Emerg Med 2017, 24(12):1483-1490.

33. Harmon KG, Clugston JR, Dec K, Hainline B, Herring S, Kane SF, Kontos AP, Leddy JJ, McCrea M, Poddar SK et al: American Medical Society for Sports Medicine position statement on concussion in sport. British journal of sports medicine 2019, 53(4):213-225.

34. Kinnaman KA, Mannix RC, Comstock RD, Meehan WP, 3rd: Management of pediatric patients with concussion by emergency medicine physicians. Pediatr Emerg Care 2014, 30(7):458-461.

35. Guerriero RM, Proctor MR, Mannix R, Meehan WP, 3rd: Epidemiology, trends, assessment and management of sport-related concussion in United States high schools. Curr Opin Pediatr 2012, 24(6):696-701.

36. Zibulewsky J: The Emergency Medical Treatment and Active Labor Act (EMTALA): what it is and what it means for physicians. Proc (Bayl Univ Med Cent) 2001, 14(4):339-346.

37. Rieger B, Lewandowski L, Potts H, Potter K, Chin LS: Parent Knowledge and Perceptions of Concussion Related to Youth Football. Cureus 2018, 10(3):e2268-e2268.

38. Chrisman SP, Schiff MA, Chung SK, Herring SA, Rivara FP: Implementation of concussion legislation and extent of concussion education for athletes, parents, and coaches in Washington State. Am J Sports Med 2014, 42(5):1190-1196.

39. Kontos AP, Jorgensen-Wagers K, Trbovich AM, Ernst N, Emami K, Gillie B, French J, Holland C, Elbin RJ, Collins MW: Association of Time Since Injury to the First Clinic Visit With Recovery Following Concussion. JAMA Neurol 2020:e194552.

40. Goldstein IM, Kostova D, Foltz JL, Kenney GM: The impact of recent CHIP eligibility expansions on children's insurance coverage, 2008-12. Health Aff (Millwood) 2014, 33(10):1861-1867.

\section{Figures}




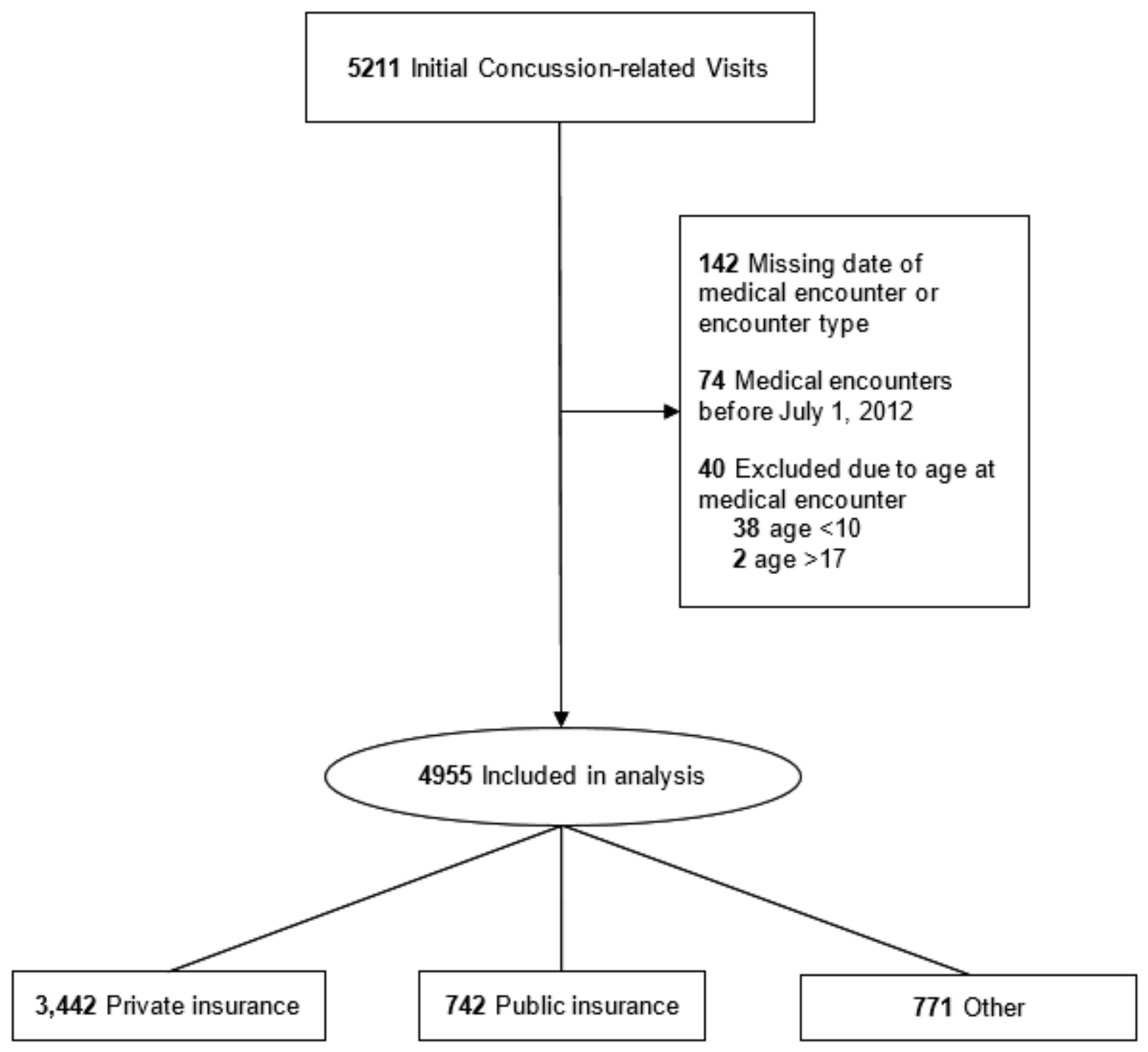

\section{Figure 1}

Flow Chart of Initial Concussion-related Visits for Inclusion Analysis 


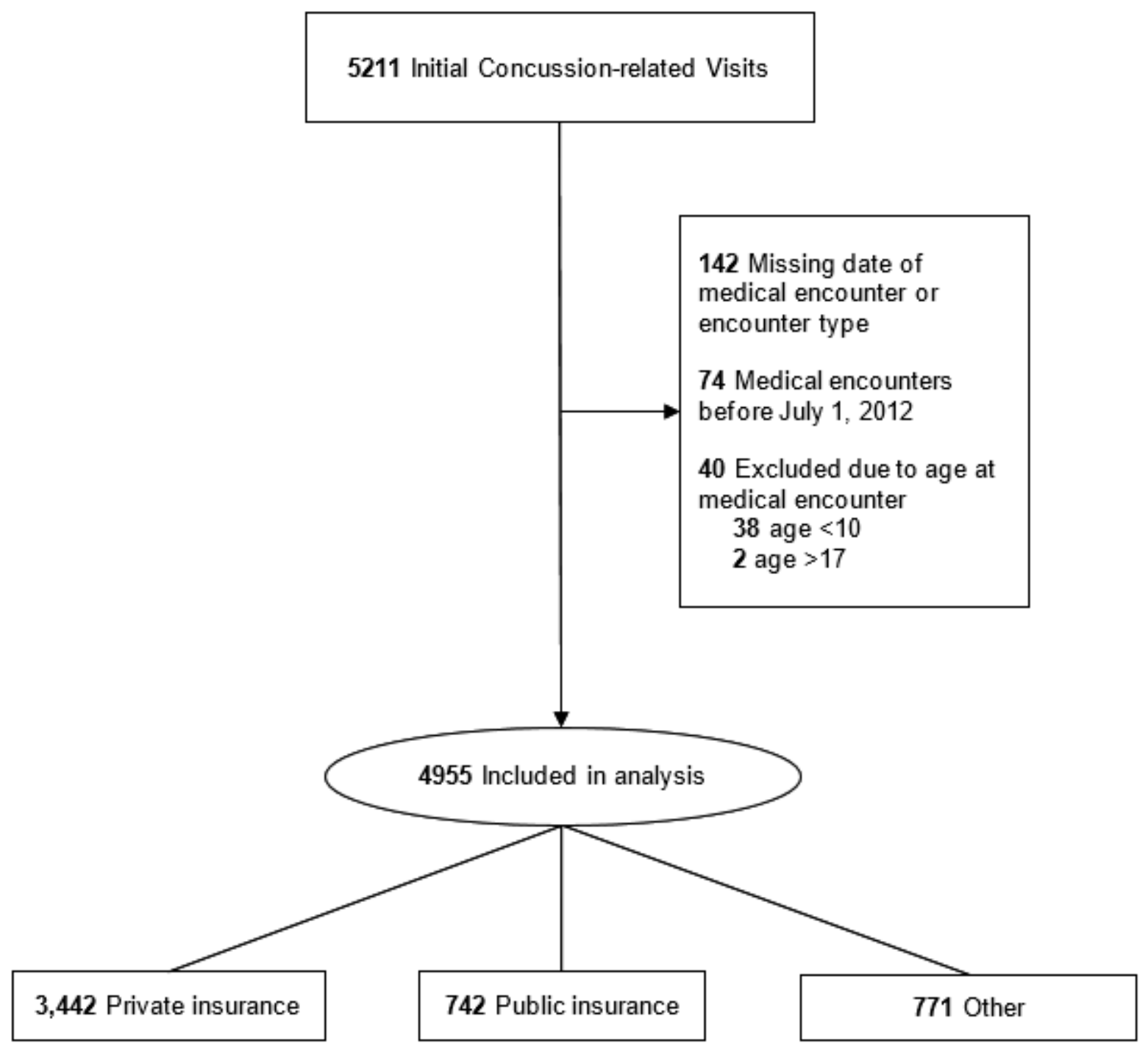

\section{Figure 1}

Flow Chart of Initial Concussion-related Visits for Inclusion Analysis 


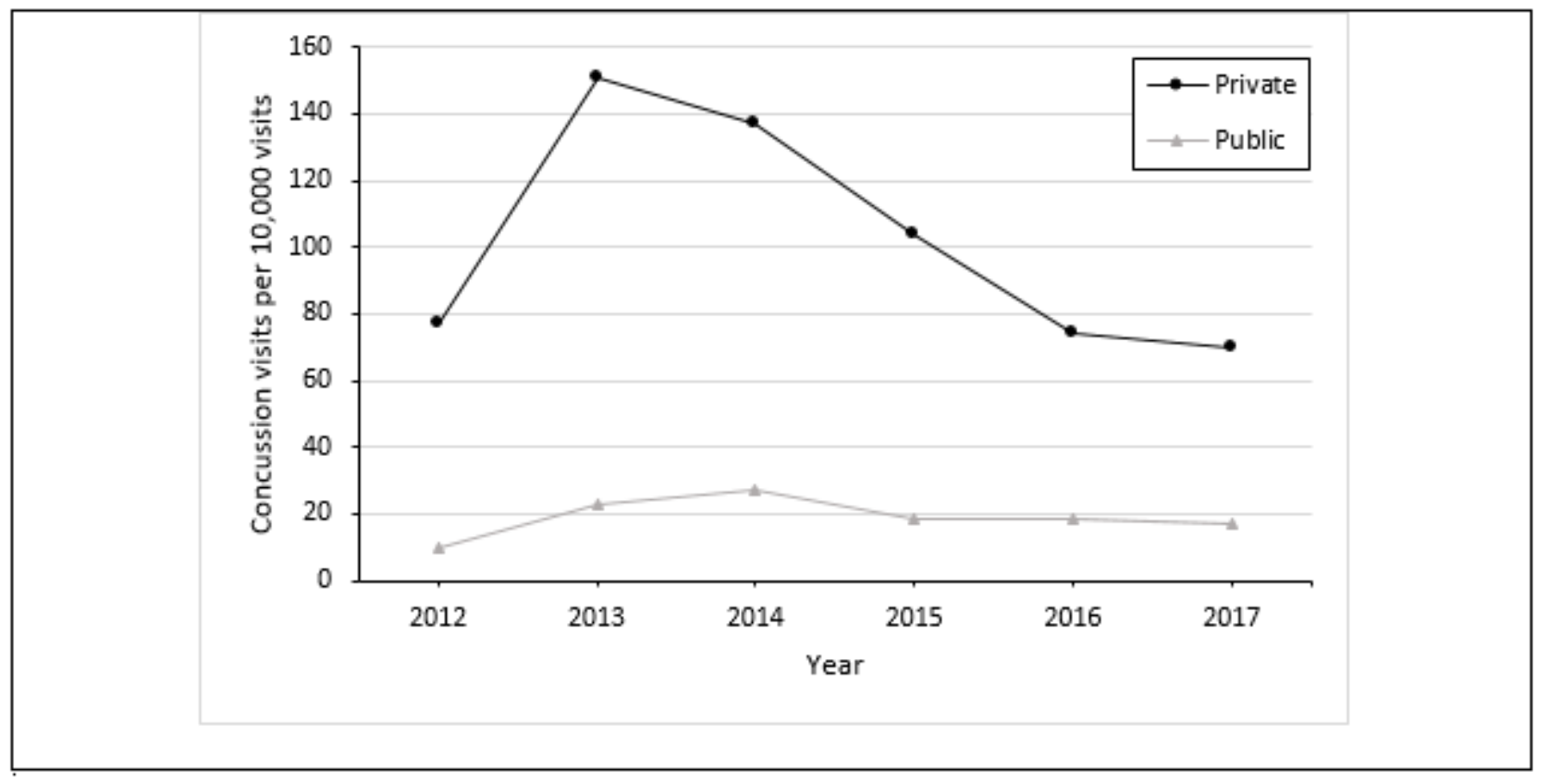

Figure 2

Rate of Initial Concussion-related Visit by Insurance Type, 2012-2017 ( $N=4,184)$ Note: Rate of concussionrelated visit was calculated as number of first visits among youth with concussions in a year divided by the total number of first visits of $\mathrm{NCH}$ patients in the same year, then multiplied by 10,000.

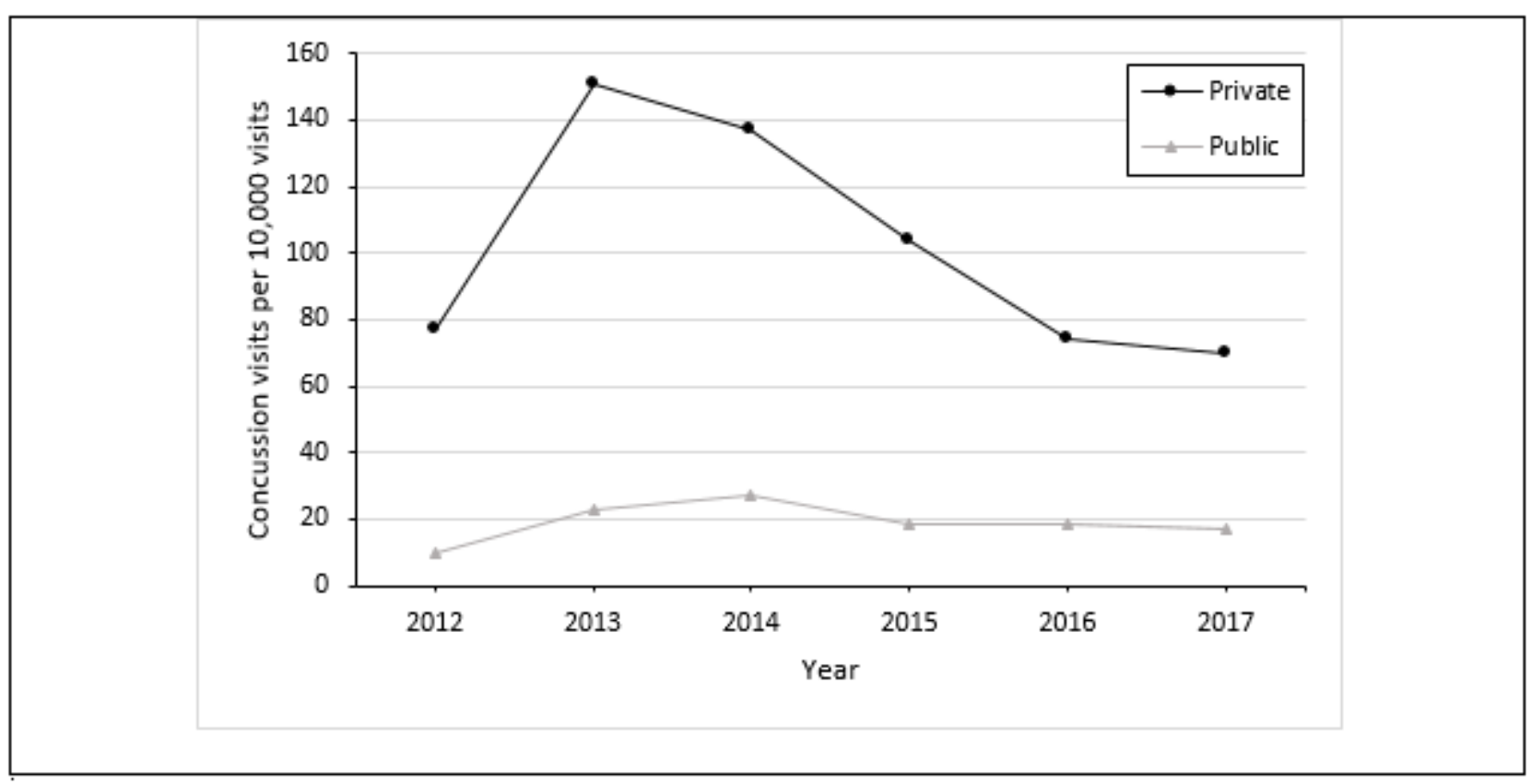

Figure 2

Rate of Initial Concussion-related Visit by Insurance Type, 2012-2017 ( $\mathrm{N}=4,184)$ Note: Rate of concussionrelated visit was calculated as number of first visits among youth with concussions in a year divided by the total number of first visits of NCH patients in the same year, then multiplied by 10,000 . 


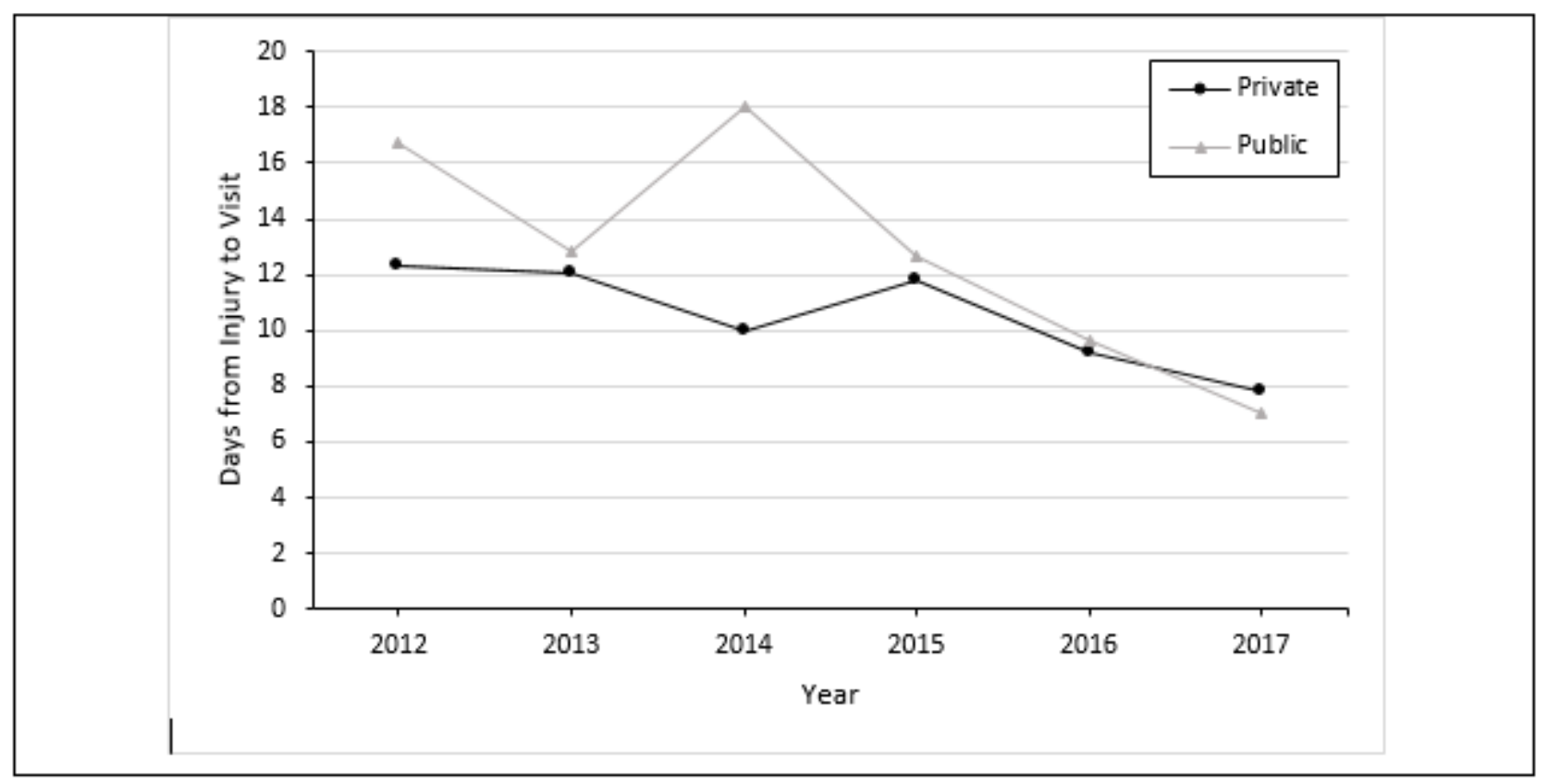

Figure 3

Days from Injury to Initial Concussion-related Visit, 2012-2017 ( $\mathrm{N}=4,184)$

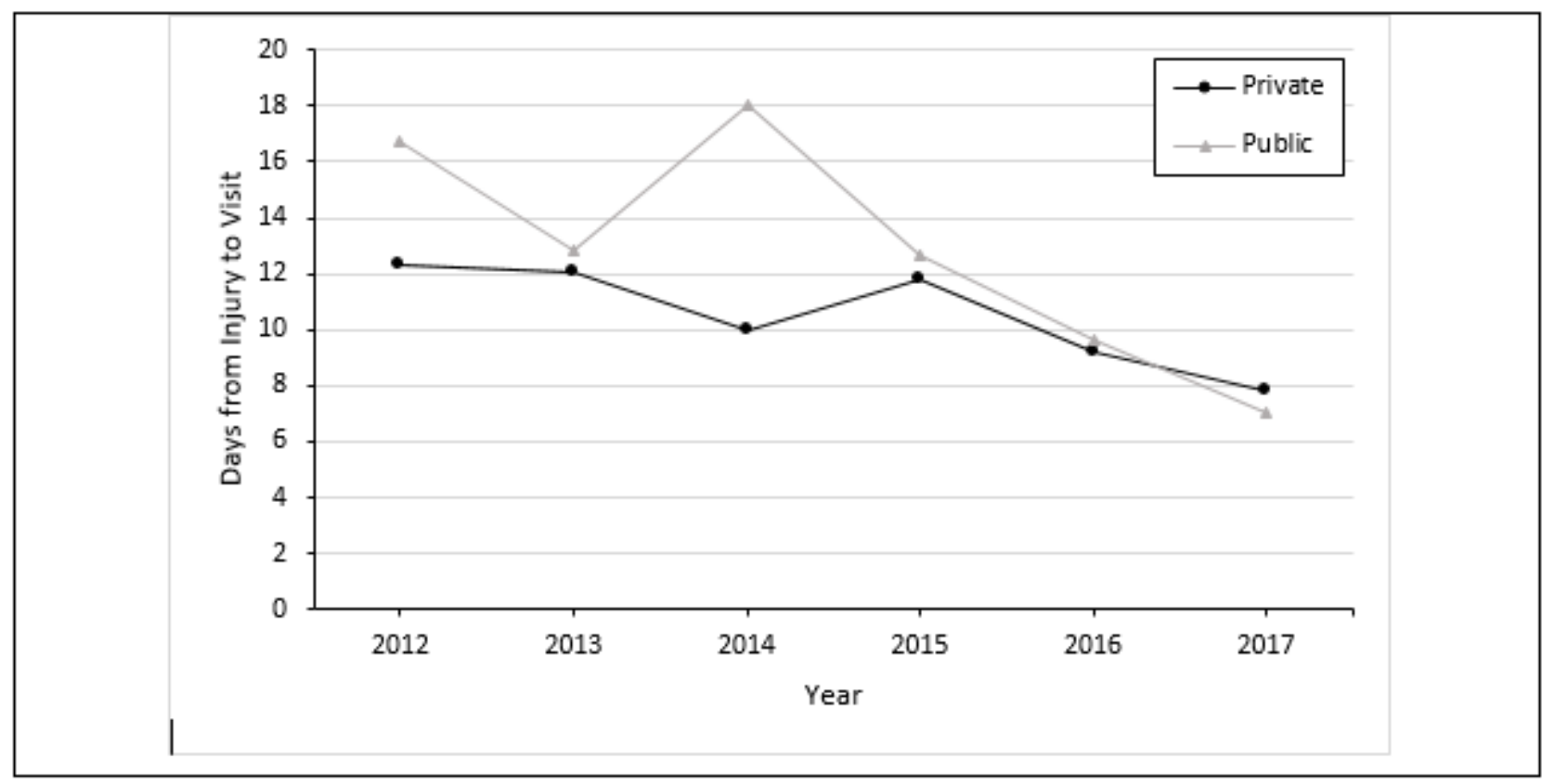

Figure 3

Days from Injury to Initial Concussion-related Visit, 2012-2017 ( $\mathrm{N}=4,184)$ 